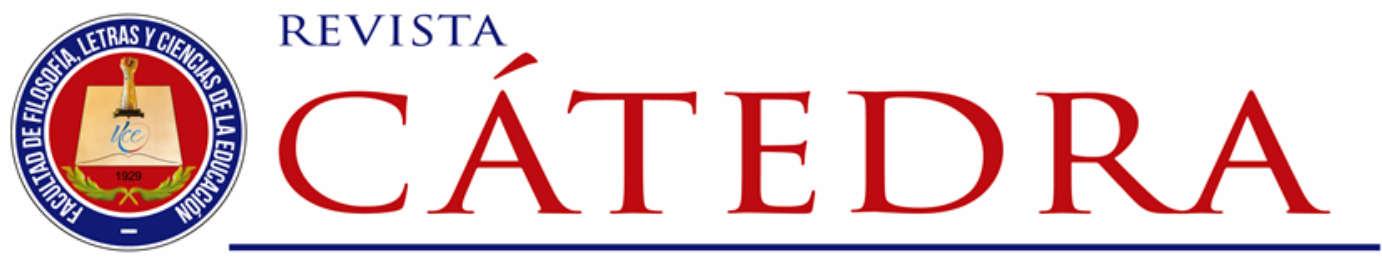

\title{
La voz reivindicativa de Gamaliel Churata y José María Memet desde la filosofía andina
}

\section{The vindicating voice of Gamaliel Churata and José María Memet from the Andean philosophy}

\author{
Glenda Viñamagua-Quezada \\ Universidad de las Fuerzas Armadas ESPE, Quito, Ecuador \\ gmvinamagua@espe.edu.ec \\ https://orcid.org/0000-0002-9514-1855
}

Paúl Puma-Torres

Universidad Central del Ecuador, Quito, Ecuador pfpuma@uce.edu.ec https://orcid.org/0000-0002-3932-7196

(Recibido: 01/09/2020; Aceptado: 05/09/2020; Versión final recibida: 11/09/2020)

Cita del artículo: Viñamagua, G., Puma, P. (2020). La voz reivindicativa de Gamaliel Churata y José María Memet desde la filosofía andina. Revista Cátedra, 3(3), 49-64.

\section{Resumen}

La literatura reivindicativa es fuente de pensamiento, resistencia y compromiso con el ser humano y con la sociedad. Estas características están presentes en las composiciones poéticas de escritores latinoamericanos que han orientado su labor hacia la literatura comprometida. Este estudio ha reunido a las voces de dos representantes de la poesía latinoamericana: Gamaliel Churata y José María Memet. Ellos abordan la temática de la reivindicación con respecto a la hegemonía occidental, así la razón de su obra poética radica en mostrar a quienes han sido relegados de la sociedad. A partir de esta premisa, el objetivo de este estudio es exponer las líneas de pensamiento desarrolladas en la producción literaria de estos dos poetas. La de Churata, configurada desde el indigenismo, mientras que la de Memet desde la poesía latinoamericana contemporánea. En ambos momentos históricos se demuestra que el pensamiento hegemónico no domina el lenguaje del arte, pues este, por sí mismo, se convierte en un espacio donde se construye la reivindicación, como una alternativa al sistema impuesto desde occidente. Para la realización de este estudio se ha empleado el método analítico-sintético y la investigación documental. Así se aplicarán los preceptos de la filosofía andina desde la visión de Josef Estermann, en el

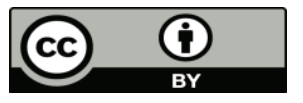


análisis interpretativo de los poemas Holocausto de todo amor para él de Gamaliel Churata y La misión del hombre de José María Memet. De esta manera se identificarán los rasgos reivindicativos que emergen en mencionadas composiciones líricas a propósito de los principios de la filosofía andina.

Palabras clave

Complementariedad, filosofía andina, poesía latinoamericana, reivindicación, relacionalidad, valores sociales.

\section{Abstract}

Vindictive literature is a source of thought, resistance and commitment to human beings and society. These characteristics are present in the poetic compositions of Latin American writers who have oriented their work towards committed literature. This study has brought together the voices of two representatives of Latin American poetry: Gamaliel Churata and José María Memet. They address the issue of vindication with respect to Western hegemony, so the reason for their poetic work is to show those who have been relegated from society. From this premise, the objective of this study is to expose the lines of thought developed in the literary production of these two poets. Churata's, configured from the indigenism, while Memet's from the contemporary Latin American poetry. In both historical moments it is demonstrated that the hegemonic thought does not dominate the language of the art, since this one, by itself, becomes a space where the vindication is constructed, as an alternative to the system imposed from the west. The analytical-synthetic method and documentary research have been used to carry out this study. Thus, the precepts of Andean philosophy will be applied from Josef Estermann's vision, in the interpretative analysis of the poems Holocaust of All Love for Him by Gamaliel Churata and The Mission of Man by José María Memet. In this way, the vindictive features that emerge in the mentioned lyric compositions regarding the principles of the Andean philosophy will be identified.

\section{Keywords}

Complementarity, Andean philosophy, Latin American poetry, vindication, relationality, social values.

\section{Introducción}

La voz reivindicativa de los valores sociales en la poesía latinoamericana ha caracterizado a esta región a partir de los diferentes procesos históricos, que la han marcado y que remiten, básicamente, a la imposición cultural a través de la violencia. De esta manera, la literatura comprometida surge como una forma de denuncia ante la hegemonía occidental. Esta denuncia, que parte desde las manifestaciones artísticas, adquiere un carácter colectivo al asumir temas considerados como preocupaciones históricas y que han desembocado en desigualdad social. Así, Bustamante (2016) asegura:

La propuesta literaria que propicia una visión de mundo, a pesar de que se trate de un sujeto (en este caso lírico) que enuncia desde el singular, representa también una conciencia del grupo social con el que se solidariza ya que, aunque se trata de una abstracción, cuando la clase social tiene una visión de mundo similar, dicha mirada identifica la voz enunciadora con el destinatario (pág. 92). 
Las manifestaciones artísticas apelan a la sensibilidad, al despertar de los sentidos y de las emociones que se interiorizan para hacerse tangibles a través de las letras. Este revestimiento del lenguaje encierra una postura crítica, "Adorno proclama que el arte no puede limitarse a reflejar simplemente el sistema social, sino que debe actuar en el interior de esa realidad como un irritante que produce una especie de conocimiento indirecto" (Selden, 2000, pág. 46). Así se da paso a un despertar colectivo, que se siente identificado con la enunciación de la voz poética, pues "la protesta a través de la poesía es la forma a la que recurre el yo lírico para crear conciencia social, al menos en sí mismo". (Bustamante, 2016, p. 95). Esta forma de apelar a la sensibilidad del lector, a través del contenido y de la forma se ve de manera particular en el registro de dos poetas latinoamericanos Gamaliel Churata ${ }^{1}$ y José María Memet ${ }^{2}$, quienes pese a pertenecer a momentos históricos distintos, en su obra está presente el tema de la reivindicación, que se analizará en este estudio a partir de los principios de la filosofía andina.

En esta dimensión de análisis radica la importancia de este estudio, pues se considera a la filosofía andina como un agente de reivindicación por dos razones. La primera porque muestra una visión que permanece relegada del paradigma hegemónico occidental, pues da cabida a aspectos que se construyen a través del sentir y del pensamiento integral. Al respecto de estas características del ser andino, Usandizaga (2009) reflexiona, sobre la visión que Gamaliel Churata manifiesta al respecto:

Tengamos en cuenta que el propio Churata propone explícitamente sacar lo indígena y lo popular del lugar a donde fue confinado; entonces, explorar en el resultado que logra, sin hacernos caer en la tentación de desdibujar las jerarquías, nos permite ir más allá de las rígidas separaciones entre la cultura hegemónica y la subordinada en los Andes (pág. 149).

El trabajo literario de Churata se manifiesta desde lo andino, como una suerte de revertir la idea de que "en todas las sociedades donde la colonización implicó la destrucción de la estructura social, la población colonizada fue despojada de sus saberes intelectuales y de sus medios de expresión exteriorizantes u objetivantes" (Quijano, 2007, pág. 123). Esta afirmación parecería revertirse en la obra de Churata, pues en ella laten formas de reivindicación de una cultura que se pretendió anular. Estos factores reivindicativos radican en el empleo del idioma quechua en la elaboración de su obra, al que intercala con el español y en las temáticas que aborda y que guardan profunda relación con el tema del indígena. En la labor poética de Churata está presente este afán de mostrar lo que se catalogaría como una forma de reivindicación de las causas sociales que perviven en América del Sur y que han encontrado una voz representativa dentro del ámbito literario.

La segunda razón por la que se considera a la visión andina como una agente de reivindicación se debe a sus principios, a los que Macas (2010) define desde la lógica indígena como "los pilares fundamentales que determinan el proceso de constitución de un sistema” (pág.188). Estos cuatro principios (relacionalidad, reciprocidad, complementariedad, correspondencia) se interrelacionan entre ellos para configurar una racionalidad integral. Este artículo sin embargo se centrará en dos de ellos: el principio de

${ }^{1}$ Gamaliel Churata es el seudónimo con el que firmó su obra el escritor peruano, Arturo Peralta Miranda.

${ }^{2}$ José María Memet es el seudónimo con el que firmó su obra el escritor chileno Pedro Ortiz Navarrete 
relacionalidad y el de complementariedad, pues se manifiestan de manera tangible tanto en la obra de Gamaliel Churata como en la de José María Memet. Para definir estos dos principios se recupera lo que afirma Macas (2010):

Yananti está referido al principio de complementariedad, el mismo que manifiesta lo esencial del vínculo de contrarios; siendo contradictorios conforman la unidad, la cabalidad. Es la constitución de dos elementos componentes en uno, la concepción del mundo de la dualidad complementaria. Esto expresa lo indispensable del complemento, el ajuste entre unos y otros para dar validez a un elemento de la realidad. Por cuanto nada es incompleto, todo es integralidad, relacionalidad y complementariedad; desde su complejidad y desde la dinámica de los principios, se genera la armonía y el equilibrio (pág. 189).

En Holocausto de todo el amor para él de Gamaliel Churata el principio de relacionalidad se ve en la concepción de vida y muerte y con ello el ciclo generacional. La descendencia, no solamente se contempla desde un espacio de la heredad. Su vínculo más profundo está relacionado con lo emocional, con la mujer y con el alimento como fuentes de vida o de regreso a ella después de transitar por la muerte. En el poema La misión de un hombre de José María Memet, estos principios se manifiestan en la renovación del cuerpo a partir de la respiración y luego del latido del corazón. Esta reconstrucción del cuerpo guarda como finalidad el ánimo de la lucha por la reivindicación. El principio de relacionalidad no se remite exclusivamente a reconstruir un cuerpo físico, en el poema mencionado, pues desde la visión andina la vitalidad de estos principios se fortalece al tomar forma a través en todos los elementos del sistema, entre estos el ser humano. Con respecto a este principio Macas (2010) afirma:

Tinkuy es el principio de relacionalidad, que expresa lo sustancial del vínculo entre todos los componentes de la realidad. Nos habla de la interrelación que existe entre unos y otros elementos que constituyen un sistema. Nada esta desarticulado o desligado de lo otro. La relacionalidad constituye todo un tejido; los elementos de una realidad se entrelazan mutuamente entre sí, en función de posibilitar la totalidad, la integralidad, la vida (págs. 187-188).

Estos principios dan cuenta de la interrelación que existe entre los elementos que conforman un sistema. Al construirlos y deconstruirlos, integrarlos y reintegrarlos, se remite a la imagen de la concepción del tiempo en espiral. Esta concepción une y comprende los desprendimientos también como un espacio de vínculo y generación. Es decir, no se piensa en fenómenos duales o separados sino en situaciones que se generan una a la otra y que dan vida y motivación a un sistema.

Esta investigación reflexiona en la reivindicación de los valores sociales dentro del ámbito poético y su vinculación con los principios de la filosofía andina. Es importante señalar que, debido a las características de estas variables, ambas han sido relegadas de la visión occidental, pues su razón de ser es contraria a estos preceptos. En este punto radica la importancia de este estudio, pues se ubica a la filosofía andina como una alternativa de reivindicación, que se manifiesta en los poemas objeto de este estudio.

\section{Lenguaje poético y reivindicación}

Es vital recordar que una de las características del lenguaje literario es poner en duda la realidad. De tal forma que la transmisión de lo tradicional, que lleva a ver las experiencias y

Licencia Creative Commons Atribución 4.0 Internacional (CC BY 4.0)

Revista Cátedra, 3(3), pp. 49-64, septiembre-diciembre 2020. e-ISSN:2631-2875

https://doi.org/10.29166/catedra.v3i3.2516 
vivencias cotidianas como normales, se pone en entredicho. Esto, para dar paso a diferentes visiones, que permiten observar por encima de esas imposiciones ideológicas y experimentar otras realidades. Una de estas realidades impuestas a través de la ideología y de la cultura es la concepción hegemónica que se hereda desde occidente a través del concepto de raza y que se perpetúa a través del lenguaje.

Es en este punto, donde la función del arte se abre camino a través de la apropiación del lenguaje impuesto para la creación de otra realidad posible. Es precisamente esta apropiación, uso y transformación del lenguaje impuesto la que se vuelve una fortaleza cuando se construyen otras realidades, allí radica una de las características del lenguaje artístico.

El valor de la literatura es corporizar las energías productivas de la sociedad; el escritor no toma el mundo como algo dado sino que lo recrea, revelando su auténtica naturaleza de producto artificialmente construido. Al comunicar este sentido de la energía productiva, el escritor, más que apenas satisfacer los apetitos consumistas de sus lectores, despierta energías idénticas (Eagleton, 2013, pág. 121)

El lenguaje, al ser un artificio, se vuelve flexible, al momento de emplearlo en el quehacer literario. La ficción crea un nuevo frente que permite narrar nuevas historias posibles, desde una materia ya dada. En el caso de la poesía reivindicativa, surgen dos puntos de inflexión que hacen posible concretarla: la modernidad y el capitalismo. Estos dos conceptos han marcado las relaciones sociales, que se han sabido mantener arraigadas hasta comprenderlas como algo inherente a la humanidad, y que permite percibir como normal la estratificación social que se da en función del poder adquisitivo y de la raza, conceptos que en la práctica cumplen la función de anular al ser humano así, Echeverría (2005) menciona:

Lo que observamos entonces en la modernidad realmente es que esa posibilidad de revolucionamiento de las identidades, mestizaje y de la creación de identidades nuevas, de nuevas formas para lo humano, se encuentra reprimida, obstaculizada sistemáticamente por la forma capitalista de la modernidad (pág. 204).

La hegemonía occidental se esmera en mantener la homogenización, de tal manera que nuevas formas de ver, de manifestar y de vivir, se vetan, para imponer una única forma de existir, enmarcada desde la lógica capitalista que deviene de la modernidad. De esta manera quedan relegadas otras formas de vida y de ser en el mundo, que se anulan en función de la supremacía impuesta.

Esta búsqueda de homogeneidad es cuestionada desde el arte, debido al sesgo excluyente que la configura y principalmente porque para el arte, y para el lenguaje poético no hay verdades absolutas. Más bien, a través de la función comunicativa propia de los lenguajes artísticos, se presentan diferentes aristas que muestra otras realidades posibles donde se da cabida a quienes han sido excluidos o anulados.

De esta manera surge una de las manifestaciones artísticas que ha caracterizado a Latinoamérica, debido a la particular historia de violencia e imposición que ha configurado su presente. Para ilustrar esta comprensión de la poesía latinoamericana vital y revolucionaria en sí misma, con respecto a la poesía de otros paralelos, Roberto Fernández Retamar relata un episodio que vivió, cuando asistió al VIII congreso de la Asociación Internacional de Literatura Comparada en Budapest, 1976 sobre «La contribución de la literatura de la América Latina a la literatura universal en el siglo XX»:

Licencia Creative Commons Atribución 4.0 Internacional (CC BY 4.0)

Revista Cátedra, 3(3), pp. 49-64, septiembre-diciembre 2020. e-ISSN:2631-287

https://doi.org/10.29166/catedra.v3i3.2516 
La propia vanguardia europea, por su parte, más allá del programa al cabo reaccionario de los futuristas italianos, [...] implicaba, en sus realizaciones más genuinas (como se ve en lo mejor del surrealismo), una impugnación de los valores «occidentales» que no podía sino favorecer tal impugnación fuera del Occidente, según lo entendió desde temprano Mariátegui. [...] Uno de los logros más notables de la vanguardia latinoamericana, en consonancia con la esencia misma de la verdadera vanguardia nacida críticamente en Europa, fue su desafiante proclamación de los valores no occidentales en la América Latina. Es lo que hace Oswald de Andrade al lanzar, maduro ya el modernismo brasileño, su «Manifiesto antropófago» [...] en 1928. La Antropofagia brasileña proponía, dirá Antonio Cándido, «la devoración de los valores europeos, que había que destruir para incorporarlos a nuestra realidad, como los indios caníbales devoraban a sus enemigos para incorporar la virtud de éstos a su propia carne (Retamar, 1995, págs. 224-225).

El pensador cubano Fernández Retamar, agencia su discurso de valores latinoamericanos con la paradoja de destruir como una forma de renacimiento. De tal manera que al devorar las imposiciones que provenían de occidente se las asimilaba para que emergiera desde el pensamiento latinoamericano una vanguardia propia de la región, no occidental o impuesta. Cuya finalidad sería diferenciar las realidades presentes en esta geografía y su afectación al analizarlas bajo parámetros ajenos al propio entorno. Además de ello se plasmaría una denuncia a la homogenización que plantea la modernidad con producciones artísticas gestadas en Latinoamérica y con temas que surgirían desde la propia realidad y que a la vez funcionarían como generadoras de pensamiento crítico para desembocar en una ineludible reivindicación de los procesos que se venían gestando en estas sociedades latinoamericanas.

En este contexto, las manifestaciones literarias, a través de su uso del lenguaje serían una especie de radiografía de la realidad latinoamericana. Pues a través de ellas se vería a profundidad qué las genera y a la vez se trabajaría en diversas respuestas para comprenderlas, para enfrentarlas o para cuestionarlas. En vista de que se contemplaría en este último punto la subyugación histórica a la que occidente ha sometido a la región latinoamericana.

De esta manera, el surgimiento de la literatura comprometida en el contexto latinoamericano, se visibiliza y al mismo tiempo abre un espacio de reivindicación, a través del trabajo literario de escritores que abordan el tema de la denuncia desde su labor poética. En este punto se vuelve preciso indicar que el tema de la reivindicación ha constituido un eje articulador dentro de las manifestaciones artísticas y literarias, sin que ello signifique que se haya dejado de lado las características del lenguaje poético. Tal es así, que ni el pensamiento que genera estas obras ni la forma de representarlo se han visto limitados, sino que conviven en la creación de un producto estético.

Así, las obras que se analizan en este estudio: destacan tanto por la temática que abordan como por su alcance literario. Al respecto, Bustamante (2016) indica:

La poesía es un arma de resistencia a través del lenguaje y si bien es cierto que un producto literario no puede cambiar el sistema de injusticias, sí logra, a partir de ciertos recursos técnicos, retóricos e ideológicos, 
comunicar, dialogar con el lector, denunciar o interrogar acontecimientos sociales (págs. 104- 105).

El rol de la literatura, además de cumplir con su innata función estética a través del uso del lenguaje, materializa el pensamiento que se ha forjado en esta región con la enunciación de la voz lírica. Y en el caso de la labor poética de Churata y de Memet, este espacio de reivindicación toma forma con la presencia de los principios de la filosofía andina, que se abordan en las composiciones que se analizan en este estudio.

\section{Principios de la filosofía andina como configuradores de reivindicación social}

En este contexto se analizará el poema Holocausto de todo el amor para él ${ }^{3}$ de Gamaniel Churata y La misión de un hombre de José María Memet. Las obras seleccionadas tienen aspectos que permiten realizar un estudio comparativo. En estos elementos se identifican principios de la filosofía andina que constituyen el hilo conductor de estos poemas y a la vez configuran un espacio para la reivindicación.

Es preciso mencionar que la racionalidad andina parte de un principio integrador, tal es así que Sobrevilla (2008) afirma que "la racionalidad andina se revela -como ya se dijo antesen el principio de la relacionalidad del todo con el todo. Otros rasgos característicos de la racionalidad andina son que es simbólica, afectiva e integradora" (pág. 234). Las características que menciona Sobrevilla son evidentes en los poemas objeto de este estudio, así, Churata (1931) relaciona el alimento con un estado de afectividad y de recuperación del ser amado, en este caso un hijo muerto.

¡Ya no quiero el seno de la imilla,

ni su pezón pintado de mieles,

No quiero para mí su pierna ni su brazo:

¡serán para mi wawa que ya viene

(II: $1-22$ )

En Holocausto de todo el amor para él, Churata, vincula elementos afectivos y simbólicos en el deseo de retorno de un hijo muerto. El alimento como símbolo de vida, la leche materna como símbolo de renacimiento.

En el siguiente cuadro se relacionarán los elementos de la filosofía andina presentes en los poemas seleccionados. Además, es preciso reparar en el empleo de lengua castellana para transmitir los principios de la filosofía andina. Por medio de esta actitud transgresora se perfila una de las estrategias de reivindicación presentes en los poemas objetos de estudio.

\footnotetext{
${ }^{3}$ Holocausto de todo el amor para él, corresponde a la sección II del poema Interludio Brúnico
} 


\begin{tabular}{lll}
\hline $\begin{array}{l}\text { Holocausto de todo el amor para } \\
\text { Él }\end{array}$ & $\begin{array}{l}\text { Dimensiones } \\
\text { de análisis }\end{array}$ & $\begin{array}{l}\text { La misión de un hombre } \\
\text { José María Memet }\end{array}$
\end{tabular}

Gamaliel Churata

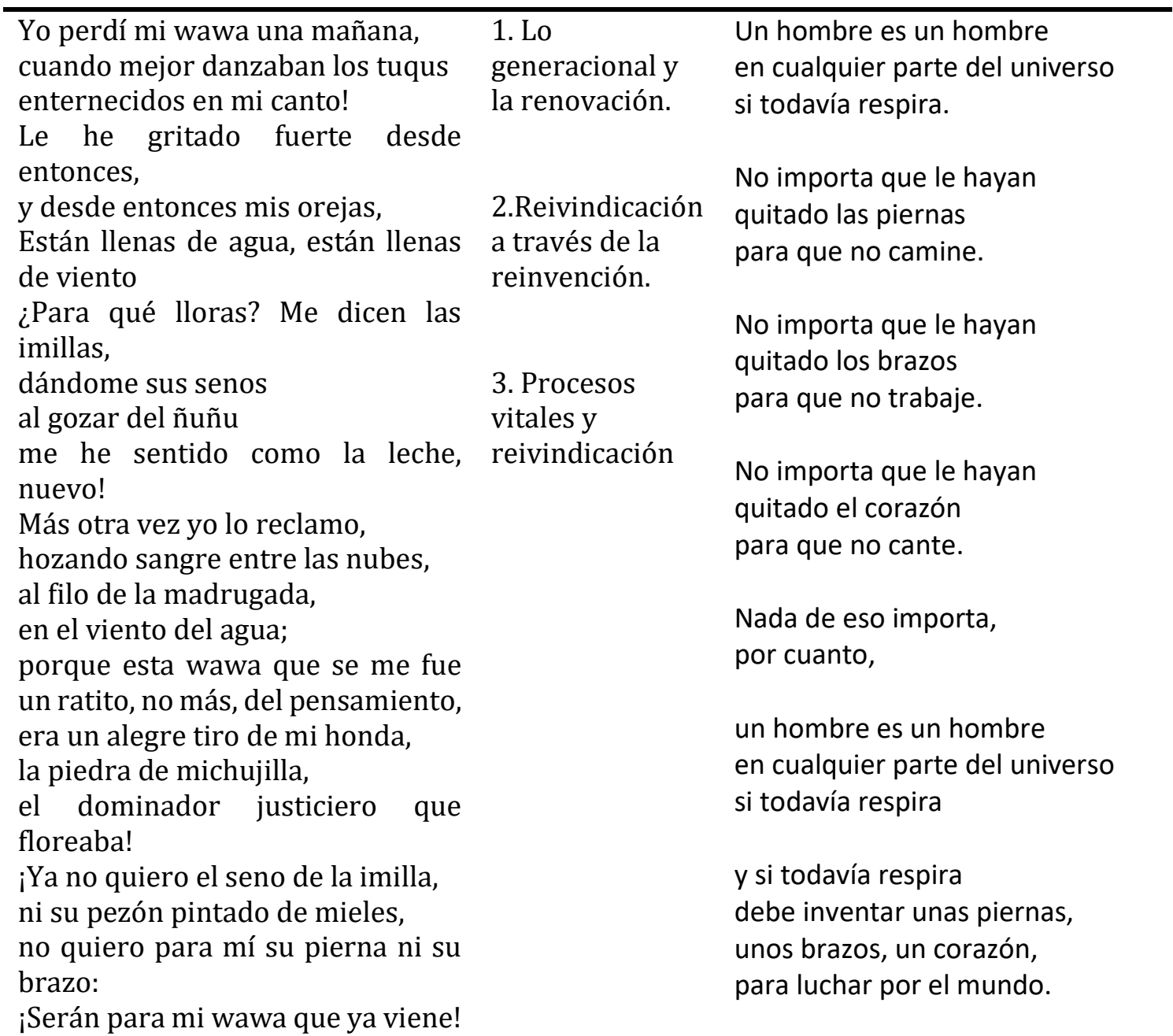

Cuadro 1. Poema Holocausto de todo el amor para él de Gamaliel Churata y La misión de un hombre de José María Memet. En el centro se encuentran los elementos en común de ambos poemas y que se analizarán bajo los preceptos de la Filosofía Andina

De acuerdo al cuadro 1, las dimensiones de análisis que se resaltan en este estudio abordan tres aspectos que se consideran significativos para comprender la lógica andina frente a aspectos como la renovación o renacimiento, la reinvensión y la vitalidad de la cultura andina. A estas dimensiones se las relaciona con los principios de la filosofía andina, que en este caso constituyen un hallazgo dentro de este estudio, así se comprende a esta forma de ver el mundo, como un espacio de reivindicación frente a la cultura hegemónica.

Con respecto a los principios de la Filosofía Andina, Josef Estermann (2006), menciona que "Se trata de principios 'lógicos' en un sentido no-occidental, es decir: principios que expresan la 'lógica andina' (su racionalidad suigeneris)" (pág. 123). Estos principios son de: 
relacionalidad, correspondencia, complementariedad, reciprocidad. En este estudio se abordará tanto el principio de correspondencia como el de relacionalidad.

El principio de la relacionalidad se comprende como un espacio de comunicación entre el ser humano y el cosmos, que "al ser una red de vínculos inacabados con el cosmos, le permite al runa en todo momento, consciente o inconscientemente, tener una relación de arriba hacia abajo, de izquierda a derecha, con cada parte del universo y asimismo, el universo se comunica con todo" (Torres, 2015, pág. 11). Esta forma de comprender las relaciones del ser humano con su entorno, permite una interconexión que dota de vitalidad y nutrición mutua a todos los elementos y entes del entorno.

Mientras que el principio de correspondencia, está vinculado con "la manera como el runa concibe la vida y se relaciona con su entorno. Sin embargo, en esta armonía y equilibrio se presenta la conflictividad, como mecanismo que libera tenciones y lima asperezas que se generan en la convivencia". (Torres, 2015, pág. 12). Todo lo que integra el universo cumple un rol, aquí radica la importancia del equilibrio como núcleo de la convivencia y la continuidad.

\subsection{Lo generacional y la muerte, un espacio para renacer}

Con respecto a este apartado, en los tres versos con que inicia el poema Holocausto de todo el amor para él, de Churata, y en los cuatro con los que lo finaliza, se lee lo siguiente:

\begin{tabular}{|c|c|}
\hline Versos de inicio & Versos de finalización \\
\hline $\begin{array}{l}\text { Yo perdí mi wawa una mañana, } \\
\text { cuando mejor danzaban los } \\
\text { tuqus } \\
\text { enternecidos en mi canto! }\end{array}$ & $\begin{array}{l}\text { ¡Ya no quiero el seno de la imilla, } \\
\text { ni su pezón pintado de mieles, } \\
\text { no quiero para mí su pierna ni su brazo: } \\
\text { ¡Serán para mi wawa que ya viene! }\end{array}$ \\
\hline
\end{tabular}

En el cuadro 2 se enfrentan los versos de inicio y de final del poema, con la finalidad de notar como en los tres primeros versos, la voz poética cuenta la pérdida de un hijo y el dolor que deviene a partir de este hecho. Mientras que los versos con que finaliza el poema si bien abordan la misma temática de pérdida, ya no se la considera como tal, sino como un retorno. Emplear la composición "ya viene" reviste al poema de un sentimiento de esperanza de un nuevo retorno. Aquí confluyen la percepción del tiempo desde la visión indígena donde nada se termina, todo se renueva y vuelve a renacer y el principio de relacionalidad, donde se comprende a la realidad como un espacio de unión de aspectos que se dan vida uno al otro, en el caso de este poema este principio toma forma en la relación que se establece entre vida y muerte, como un nuevo inicio.

Al respecto Estermann (2006) menciona: "Las categorías temporales más importantes no son 'avanzado' o 'atrasado', ni 'pasado' y 'futuro', sino 'antes' (ñaivpaq/nayra) y 'después' (qhepa/qhipa). El tiempo tiene un orden cualitativo, según la densidad, el peso y la importancia de un acontecimiento" (pág. 196). Es evidente, entonces, la concepción del tiempo, que caracteriza la cosmovisión del mundo andino, como un conjunto de hechos que se suscitan sin llegar a un fin, pues hay una renovación constante, que impide concebir a la muerte como culminación definitiva y permanente. 
De esta manera, surge el sentido de la heredad como la continuidad de lazos que unen generaciones por medio de aspectos como los afectos, ya sea por vínculos de sangre como sucede con el aspecto genealógico o por vínculos afectivos como el alimento. A este elemento es preciso analizarlo desde la perspectiva del origen de la vida, cuando se menciona a la mujer que amamanta a dos generaciones y permite el retorno de la muerte de la más joven. De esa manera se hace referencia al tiempo cíclico y se retoma el principio de relacionalidad. Al respecto Sobrevilla (2008) afirma:

El principio andino de la relacionalidad sostiene que no puede haber ningún ente carente de relaciones o absoluto; y positivamente expresado: este principio afirma que cada ente o acontecimiento se halla inmerso en múltiples relaciones con otros entes, acontecimientos, estados de conciencia, sentimientos, hechos y posibilidades (pág. 234)

En los versos citados en el cuadro 2, existe el vínculo entre lo femenino como origen de la vida, el alimento, en la forma de leche materna y miel con la espera, el renacimiento del hijo que se fue y la renuncia a la vida por parte del progenitor, para que el hijo muerto retorne. De esta manera la generación se renueva y la vida se conserva como un espacio de esperanza. Así, vida y muerte se relacionan como una serie de elementos que se generan uno al otro, donde el fin no se concibe desde la visión occidental, sino como el inicio de nuevos procesos y experiencias.

Con respecto al principio de complementariedad, y su relación con el poema de Churata es preciso recurrir a lo que afirma Guerrero (2010):

Un rasgo de las sabidurías andinas, es el que dicha complementariedad, se hace posible mediante la interacción simbólica, celebrativa y ritual, no epistémica, conceptualmente, sino simbólicamente, ritualmente, corporalmente, vivencialmente, existencialmente, a través de las diversas tramas de sentido que el Runa teje desde su cultura, para dar sentido a la totalidad de su existencia dentro de este infinito cosmos (pág. 500)

La ritualidad que encierra el proceso de alimentación como un acto que genera la vida, se encuentra en la mujer, en la imagen de la imilla 4 . Ella brinda el alimento que generan sus senos, a un padre que perdió a su hijo, y él a su vez reniega de esta vitalidad, para devolvérsela al hijo, de quien ansía su regreso.

¿para qué lloras? Me dicen las imillas

dándome sus senos

al gozar del ñuñu

me he sentido como la leche, nuevo!

$[\ldots]$

¡Ya no quiero el seno de la imilla,

ni su pezón pintado de mieles,

no quiero para mí su pierna ni su brazo:

¡serán para mi wawa que ya viene! (II: 1-22)

La ritualidad, a través del principio de complementariedad vincula a dos generaciones, pese a que ya no comparten el mismo espacio. "El Interludio desarrolla una historia, un encuentro entre un personaje y un mundo más allá de la vida" (Medinaceli, 2020, pág.102). Muerte y

${ }^{4}$ En quechua y aymara, Imilla significa mujer joven. 
vida no están separadas, sino que se engendran recíprocamente a través de la imagen de la mujer y del alimento que de ella emana. "La condición sexual no solo 'complementa' lo que por sí solo es deficiente y 'a medias', sino que además 'genera' vida y conserva los grandes ciclos vitales”. (Estermann, 2006, pág. 226). A través de este fundamento de la filosofía andina, se plasma la simbología de los opuestos ante el resurgimiento de una nueva vida.

La forma de comprender el mundo a partir de la filosofía andina, se fundamenta en aspectos que apelan a la sensibilidad, a la afectividad, a los sentimientos, como parte integral e inherente del ser humano 'La sensibilidad y sensitividad andinas no dan preferencia al 'ver', y por lo tanto, la racionalidad cognoscitiva no es en primer lugar 'teórica' (theorein), sino más bien emocio-afectiva" (Esterman, 2006, pág. 113). A partir de estos principios se comprende la simbología presente en el poema de Churata, como el regreso a la vida, que surge desde el amor paterno y desde el alimento que emana del seno de la mujer. Contrario a visión occidental, donde los principios que rigen este pensamiento se sustentan en el ver y en la comprobación.

\subsection{Reivindicación a través de la re-invensión}

Dentro de este contexto, se puede observar en el cuadro 3, cómo se aborda la temática de la concepción del tiempo en el poema La misión de un hombre de José María Memet. Donde se encuentra la misma estructura que se analizó en el poema de Churata, pues se vinculan el inicio del poema con sus versos finales. En este caso existe una variable que le brinda al poema una sensación de continuidad de ideas, en las que permanecen latentes una serie de posibilidades, donde no se admite un fin. Esta idea se genera a partir de vincular a la respiración con la fuente de vida, que reconstruye el cuerpo para darle sentido.

\begin{tabular}{ll}
\hline Versos de inicio & Versos de finalización \\
\hline Un hombre es un hombre & y si todavía respira \\
$\begin{array}{l}\text { en cualquier parte del universo } \\
\text { si todavía respira. }\end{array}$ & $\begin{array}{l}\text { debe inventar unas piernas, } \\
\text { unos brazos, un corazón, } \\
\text { para luchar por el mundo. }\end{array}$ \\
\hline
\end{tabular}

Cuadro 3. Versos de inicio y del final del Poema La misión de un hombre de José María Memet

Con respecto al valor de la conexión del ser humano con su propio ser a través de los sentidos se reflexiona en los principios de la filosofía andina, cuya concepción orienta hacia la comprensión del entorno a través de sensaciones que provienen del interior del ser humano. En ese espacio se encuentran un eslabón que conecta este interior con elementos vitales del entorno. Es allí donde se apela a la función de los sentidos, así como a la respiración o el latido, para establecer un medio de conexión con el entorno que permita explorar espacios vitales, que no solamente sean aprehendidos a través de la visión. Así, Estermann (2006) afirma:

La filosofía andina enfatiza las facultades no-visuales en su acercamiento a la realidad. El tacto, por ejemplo, es un sentido privilegiado (solo hay que pensar en la devoción religiosa o en la expresión de cariño), pero también el olfato y el oído (pág. 112) 
Bien puede vincularse esta relación latente entre sentidos y acercamiento a la realidad, con el valor que se brinda al acto de respirar, como generador de vida. De esta manera, la reconstrucción del ser, se orienta hacia la reinvención del cuerpo motivado por un afán de reivindicación y de lucha. La interiorización de estos conceptos encuentra un espacio en el principio de "la relacionalidad de todo, la red de nexos y vínculos que es la fuerza vital de todo lo que existe. No 'existe' (en sentido muy vital) nada sin esta condición trascendental". (Estermann, 2006, pág. 110). Este principio lo podemos leer en los versos de Memet, cuando se establece un vínculo entre la respiración con el resurgimiento de piernas, brazos y corazón.

Al respecto, Estermann (2006) manifiesta: “El runa/jaqi 'escucha' la tierra, el paisaje y el cielo; 'siente' la realidad mediante su corazón” (pág. 113). La filosofía andina revierte la lógica occidental de acercarse o comprender el mundo a través del ver, y da paso al sentir, de esta manera establece sus relaciones con el entorno y con su propia constitución. La lógica andina se fundamenta en priorizar las sensaciones y en comprender los fenómenos internos y externos desde la lógica del corazón. Así, se constituyen los principios de la Filosofía Andina, cuyo espacio de enunciación parte desde ámbitos más integradores. Al respecto, Guerrero (2010) menciona:

Es imprescindible empezar a construir un saber corporeizado, pues la realidad se inscribe en el cuerpo y el cuerpo habla; que aprendamos a mirar la realidad, no solo desde dos externo preceptores que priorizó el positivismo, como criterio de verdad y objetividad, la mirada y el oído; pues si pretendemos comprender la totalidad del sentido de la realidad y de la existencia, es necesario incorporar la totalidad de los otros sentidos, la totalidad del cuerpo como posibilidades de conocimiento. (págs. 503504)

En el poema de Memet la idea de reinvención del cuerpo toma como base su reconstrucción a partir de dos momentos considerados clave dentro de la filosofía andina: la respiración y el corazón. Ambos apelan al interior del ser, pues su propia naturaleza, permite que se alejen de la forma conceptual y visible de acercarse al mundo. Sin embargo, luego se proyectan hacia el exterior, para reflexionar en las funciones motrices del cuerpo, encaminadas a la lucha por el mundo. En estos espacios confluye una dicotomía, mientras la una vertiente dirige hacia el pensamiento occidental (ver), la otra refiere al pensamiento andino (sentir). Así, se deja de lado al concepto como principal configurador del pensamiento, al respecto, Orrego (2015) afirma:

Por otra parte, la categoría misma de "concepto" es ajena al pensar indígena, no por adolecer este de términos para expresar las ideas, representaciones mentales y experiencias del sujeto, sino por la idea logo-céntrica que tras la explicación del mundo por medio del concepto se esconde (pág. 49).

Cuando se prioriza al sentir como una forma de comunicación con el entorno, se contemplan factores que vuelven dialogal la relación del ser humano tanto en su interior como en su exterior. De esta manera, se nota un ser integral que se construye en tanto su relación interna como en su relación con elementos exteriores, así se comprende el principio de complementariedad. Al respecto, Guerrero (2010) afirma: "Por lo tanto, si todo en el cosmos está articulado, ningún ser, hecho, proceso, fenómeno, problemática puede ser mirado de forma fragmentada, sino en sus interrelaciones múltiples, en su profunda complejidad y 
complementariedad, en su multicausalidad" (pág. 501). Estas múltiples interrelaciones se leen en el poema La misión de un hombre de Memet (2019) cuando menciona en sus versos:

1. Un hombre es un hombre

2. En cualquier parte del universo

3. Si todavía respira

4. No importa que le hayan

5. quitado las piernas

6. para que no camine.

7. No importa que le hayan

8. quitado los brazos

9. para que no trabaje.

10. No importa que le hayan

11. quitado el corazón

12. para que no cante.

13. Nada de eso importa, 14. por cuanto,

15. un hombre es un hombre

16. en cualquier parte del universo

17. si todavía respira

18. y si todavía respira

19. debe inventar unas piernas,

20. unos brazos, un corazón

21 para luchar por el mundo.

(Misión de un hombre, pág. 18)

En los versos centrales 10,11 y 12, la voz poética relaciona al corazón con el canto, lo que apela al sentir, característica propia de la visión andina, sin embargo, lo vincula con acciones que remiten a lo visible como la palabra camina, en el sexto verso o trabajar en el noveno verso. Colocar como parte central del poema, al corazón (verso 10) y relacionarlo con el canto (verso 12) transmite la idea que desde allí se bifurcan las demás posibilidades que permiten la acción tangible en el ser humano.

La mitad del poema constituye una suerte de epicentro de la espiral, los versos anteriores remiten a una ausencia de piernas (verso 5) que impiden caminar (verso 6). Mientras que el verso 8 da cuenta de ausencia de brazos, que impiden trabajar (verso 9). Los versos centrales, que emular el cuerpo humano, con una fuerza centrífuga que orienta al corazón indican que desde allí se formará un nuevo cuerpo, a partir de la respiración (verso 17). Se unen corazón, canto y respiración, acciones intangibles relacionadas con el sentir, para dar paso a las partes tangibles del cuerpo invención de piernas (verso 19) aparecimiento de brazos (verso 20). Tanto piernas como brazos, extremidades del cuerpo, se unen al corazón, órgano interno, para recobrar la vida y encontrar una funcionalidad que vincule tanto el ver como el sentir. Así en el último verso se lee: luchar por el mundo. 
El principio de complementariedad toma cuerpo en este poema, cuando se vincula un órgano interno y central del cuerpo con las extremidades, para proporcionarles un sentido profundo, una nueva vida con un objetivo renovado: luchar por el mundo. Para contextualizar al significado de la palabra lucha desde la filosofía andina, es preciso comprenderla desde el sentido de la vida, al respecto Estermann (2013) menciona: "me refiere a la concepción de la 'vida' que juega un papel primordial a la hora de pensar en la convivencia cósmica y en el ideal andino del "Vivir Bien”. (pág. 5) Así, la lucha y la vida están relacionadas con una convivencia armónica.

\section{Conclusión}

En este contexto, es preciso manifestar que la poesía es fuente de pensamiento y resistencia frente al poder. Ella tiene la capacidad de reconocer y desmantelar el paradigma hegemónico que rige a naciones y se transmite a través de ideologías. En los poemas de Churata y Memet, se describe a un ser desplazado de la sociedad, que retoma sus principios filosóficos para refundarse como un acto de resistencia y reivindicación.

Por medio del lenguaje poético, la filosofía andina toma forma para describir a través de la relacionalidad y de la complementariedad el entramado que se teje entre los elementos que forman un sistema. En Holocausto de todo mi amor para él, de Gamaliel Churata, se identifica la vitalidad de este principio en la concepción de vida y de muerte. Estas dos manifestaciones que desde la visión occidental son contrapuestas, tienen un vínculo de generación desde la filosofía andina. Tanto vida como muerte comparten los mismos espacios y su relación se fundamenta en el surgimiento de la vitalidad en las nuevas generaciones, con las que se compartirá los mismos valores y cosmovisiones. Entonces el dolor que causa una muerte, desde la visión occidental, desde la filosofía andina se convierte en esperanza de un retorno. De esta manera, se considera que una manera de reivindicar es retomar la herencia cultural desde las nuevas generaciones.

Estos principios están presentes en La misión de un hombre de José María Memet en la regeneración de un cuerpo que se desintegra debido a la lucha por revindicar sus derechos. En este proceso de regeneración intervienen factores que apelan a una forma de sentir la vida a partir de la respiración y del corazón, ambos espacios han sido relegados desde la visión de occidente, donde se prioriza el ver y se sobrepone lo tangible. Como contraparte de este pensamiento, la filosofía andina brinda la posibilidad de ver, de reconstruir y de volver a la vida desde dos vertientes: sentir y luchar. Estos principios de la filosofía andina toman cuerpo a través de esta construcción poética porque brindan a la posibilidad de que el objetivo de la lucha sea el equilibrio y la integralidad, mas no la subyugación y el derrocamiento de una herencia cultural.

Si bien Churata y Memet pertenecen a periodos y tendencias distintas, los vincula la perspectiva de reivindicación que dirige su sentir y su labor hacia los sectores excluidos de la sociedad. Lo significativo de este estudio radica en que se toma una filosofía desterrada de la visión occidental para validar la denuncia que se manifiesta a través de la voz poética. Es decir, dos formas de manifestación que han sido desterradas del poder hegemónico, como la resistencia cultural presente en la poesía y los principios de la filosofía andina, se recuperan una a la otra en un afán de reivindicación y así se da cuenta de un arte comprometido

Licencia Creative Commons Atribución 4.0 Internacional (CC BY 4.0)

Revista Cátedra, 3(3), pp. 49-64, septiembre-diciembre 2020. e-ISSN:2631-2875

https://doi.org/10.29166/catedra.v3i3.2516 


\section{Bibliografía}

Bustamante, G., Bañuelos, J., Bohórquez, A. (2016). La poesía como resistencia y representación social. Recuperado de:

\section{http://www.scielo.org.mx/pdf/ap/v37n2/0185-3082-ap-37-02-00087.pdf}

Echeverría, Bolívar. (2005). Vuelta de siglo. México: Fundación editorial el perro y la rana.

Eagleton, T. (2013). Marxismo y crítica literaria. Buenos Aires: Paidos.

Estermann, J. (2006). Filosofía Andina, Sabiduría indígena para un mundo nuevo. La Paz: ISAET.

Estermann, J. (2013). Ecosofía Andina. Recuperado de:

\section{https://www.uraqi.cl/filosofia-andina/}

Guerrero, Patricio. (2010). Corazonar. Una antropología comprometida con la vida. Miradas otras desde Abya Yala para la decolonización del poder, del saber y del ser. Quito: Ediciones Abya Yala.

Macas, L. (2010). El Sumak Kawsay. Antonio Hidalgo Capitán (Ed.) Huelva: Centro de investigación de migraciones, pp. 179-192.

Medinaceli, A. (2020). Hito radical: una lectura de interludio bruníldico. Recuperado de: https://ddd.uab.cat/pub/mitologias/mitologias a2020v21/mitologias a2020v21p99.pdf

Memet, J. (2019). Mapuche, la tribu de las palabras. Recuperado de : https://www.escritores.cl/ediciones/articulos2/Libro-Mapuche-Jose-MariaMemet-2020.pdf

Orrego, I. (2015) Descolonialización epistémica. Aportes del pensar andino abyayalanse a la

Filosofía. Recuperado de:

https://revistas.usantotomas.edu.co/index.php/cfla/article/view/2199

Quijano, A. (2007). Colonialidad del poder y clasificación social. Santiago Castro-Gómez, Ramón Grosfoguel (Comp.) Bogotá: Siglo del Hombre Editores, pp. 93-126

Retamar, R. (1995). Para una teoría de la literatura hispanoamericana. Santafé de Bogotá: Instituto Caro y Cuervo

Selden, R. (2000). Teoría literaria contemporánea. Barcelona: Ariel

Sobrevilla, D. (2008). La filosofía andina del P. Josef Estermann. Quito: Abya Yala, pp. 231247

Torres, E. (2015). "El rol de la mujer indígena en la comunidad inti waykupunku del cantón otavalo-provincia de Imbabura”. (tesis de pregrado) Pontificia Universidad Católica del Ecuador, Quito.

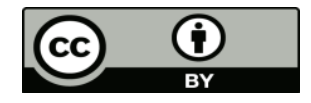


Usandizaga, H. (2009). El pez de oro, de Gamaliel Churata, en la tradición de la literatura peruana. Recuperado de https://www.researchgate.net/publication/279509510 El pez de oro de Gamali el Churata en la tradicion de la literatura peruana

\section{Autores}

GLENDA VIÑAMAGUA-QUEZADA Licenciada en Ciencias de la Educación Especialización en Letras y Castellano por la Pontificia Universidad Católica del Ecuador, Magíster en Estudios del Arte por la Universidad Central del Ecuador. Egresó de la Maestría en Literatura Ecuatoriana e Hispanoamericana de la Pontificia Universidad Católica del Ecuador.

En la actualidad es docente en la Universidad de las Fuerzas Armadas ESPE. Laboró en la Universidad de las Américas, en la Escuela Politécnica Nacional, en la Universidad UTE y en La Universidad Central del Ecuador. Escribió para la Revista Anaconda Arte y Cultura, para la Revista Artes de Diario La Hora. Fue Correctora de Estilo en Revista Diplomacia del Ministerio de Relaciones Exteriores y en Diario La Hora. Participó como jurado de la Categoría Literatura en el "Sistema Nacional de Fondos Concursables para las Artes y Fondo Editorial" Organizado por el Ministerio de Cultura.

PAÚL PUMA-TORRES Licenciado en Comunicación Social, Especialización en Comunicación Impresa por la Universidad Central del Ecuador, Magíster en Estudios de la Cultura Mención Literatura Hispanoamericana por la Universidad Andina Simón Bolívar, Doctorando en Literatura Hispanoamericana por la Facultad de Letras de la Universidad de Alicante, España.

Escritor, crítico literario y editor ecuatoriano. Ha publicado alrededor de veinte libros en todos los géneros literarios. Docente de la Carrera de Pedagogía de la Lengua y la Literatura. Ex Director de la Carrera de Pedagogía de la Lengua y la Literatura de la Universidad Central del Ecuador (2019), Premio FACSO (UCE, 1994), por La teoría del absurdo, Premio Nacional de Literatura Aurelio Espinosa Pólit de Poesía (Editorial Planeta, 2002) por Felipe Guamán Poma de Ayala, Mención de honor Juegos Florales (Ambato, 2013) por Filamentum, Premio Universidad Central del Ecuador (Cascahuesos, 2016) por B2, Premio Gobierno de la Provincia de Pichincha (2017) por Sharapova, Premio Joaquín Gallegos Lara (2017) por Mickey Mouse a gogo. 